\title{
Evaluation of genetic diversity in Brassica L. species and cultivars through application of microsatellite markers
}

Klimenko I.A., Dushkin V.A., Antonov A.A.*

Federal Williams Research Center of Forage Production and Agroecology, Lobnya, Russia

* email: antonov4B@yandex.ru

Genetic diversity analysis and identification of populations, lines and cultivars is an important aspect for breeding material evaluation, protection of breeder's rights and choice of promising strategies for developing samples with improved characteristics. The objective of this investigation was to study genetic variability and relationships in a collection of rapeseed (Brassica napus L.) and summer rape (Brassica rapa L.) cultivars, that were developed by breeders of Federal Williams Research Center of Forage Production and Agroecology A total of 15 rapeseed and 3 summer rape cultivars (winter and spring type) were used for DNA-polymorphisms identification with 13 microsatellite (SSR) markers, derived from data base «Brassica.info» (https://www.brassica.info). Genomic DNA was extracted using modified SDS-method from «bulk-sample» of 30 seedlings per each cultivar. The PCR reaction was performed in a total volume of $20 \mu \mathrm{l}$, containing $20 \mathrm{ng} / \mu \mathrm{l}$ of DNA according to conditions, proposed by Chandra et al. (2013). The temperature of hybridization was in range from 46 to $51{ }^{\circ} \mathrm{C}$ for each primer pairs. PCR products were separated by electrophoresis on $4 \%$ agarose gel (MetaPhor ${ }^{\mathrm{R}}$ Agarose, USA). Statistical treatment of the results was carried out using Excel Microsatellite Toolkit and PopGene software. A final set of 8 SSR primers pairs were selected from initial ones $13(61 \%)$ based on their polymorphism and repeatability. These primers produced 315 bands in the 18 samples under study (average of 17.5 bands per reaction). Size of amplified DNA fragments was in the range of 132 to $1000 \mathrm{bp}$ (Table 1). The average parameter of heterogeneity was 0.21 . Primer pairs Ni2C12, Ni03H07a Ni2C12 and Bna.M.010 were able to detect differences between cultivars of summer rape, the other ones were useful for distinguish the species and types of samples. Obtained data showed, that microsatellite markers are useful tool to find interspecies differences in Brassica genera, as well as to discriminate spring from winter types, however, additional set of markers is necessary for cultivars identification.

Table 1. Characteristics of SSR markers used for DNA-polymorphism in Brassica napus L. and Brassica rapa L. cultivars

\begin{tabular}{lcccc}
\multicolumn{1}{c}{ Marker } & Allele number & $\mathrm{He}$ & Effective number of alleles & Allele size range, bp \\
Na12A02 & 5 & 0.32 & 1.54 & $159-209$ \\
Ni2C12 & 3 & 0.13 & 1.67 & $110-140$ \\
Bna.M.009 & 5 & 0.40 & 0.40 & $165-370$ \\
Bna.M.010 & 3 & 0.19 & 1.25 & $145-173$ \\
Ni03H07a & 8 & 0.47 & 1.88 & $132-1000$ \\
NiF02a & 5 & 0.15 & 1.20 & $175-736$ \\
Ol10A03a & 8 & 0.21 & 1.29 & $166-919$ \\
Ol10F11a & 5 & 0.17 & 1.22 & $135-179$ \\
Average & 5.25 & 0.21 & 1.31 &
\end{tabular}

